\title{
Do infanticides occur in harem-forming equids? A test with long-term socio- demographic data in wild plains zebras.
}

\author{
Camille Vitet ${ }^{1,2} *$, Patrick Duncan ${ }^{2,3}$, Andre Ganswindt ${ }^{4}$, Cheryl Mabika ${ }^{5}$ \& Simon Chamaillé-Jammes ${ }^{1,2,4}$ \\ ${ }^{1}$ CEFE, Univ. Montpellier, CNRS, EPHE, IRD, Univ. Paul Valéry Montpellier 3, Montpellier, France \\ ${ }^{2}$ LTSER France, Zone Atelier "Hwange", Hwange National Park, Bag 62 Dete, Zimbabwe - CNRS HERD (Hwange \\ Environmental Research Development) program \\ ${ }^{3}$ Centre d’Etudes Biologiques de Chizé, CNRS-UMR 7372, Villiers-en-Bois, France \\ ${ }^{4}$ Mammal Research Institute, Department of Zoology \& Entomology, Faculty of Natural and Agricultural \\ Sciences, University of Pretoria, Hatfield 0028, South Africa \\ ${ }^{5}$ Zimbabwe Parks and Wildlife Management Authority, Scientific Services, P.O. Box CY140, Causeway, Harare, \\ Zimbabwe
}

*Corresponding author:

Name: Camille Vitet

Address : CEFE, 1919 Route de Mende 34293 Montpellier, France

Telephone number: 04.67.61.32.69

E-mail address: camille.vitet@gmail.com 


\section{ABSTRACT}

Social dynamics can play a major role in shaping the population ecology and evolutionary trajectory of a species. This is for instance the case in species known to experience infanticide when a dominant male is replaced by another. Infanticide by males has been observed in many taxa, mostly in species that breed year round and in which a few males monopolize reproduction. In such species, infanticide often occurs after takeovers of breeding groups, and the frequency of takeovers often increases with increasing female group size, therefore raising the risk of infanticide in larger groups. Among ungulates, male infanticide has been reported mostly in harem-forming equids in captive populations, usually following harem-male turnover. In this study, we empirically tested in the wild whether the rate of stallion (i.e. harem-male) turnover increases with the number of reproductive females in harems, and whether these events reduce foal survival. We used a long-term study of wild plains zebra (Equus quagga) of Hwange National Park, Zimbabwe, where, for more than 15 years, stallion turnovers were recorded and accurate data on pregnancy were obtained by hormone assays. We show that stallion turnovers are frequent and, as expected, particularly in harems with a large number of reproductive females. We then show that foal survival did not differ significantly between situations when a stallion turnover occurred shortly before or after their birth and when it did not. This result was consistent with the fact that no attacks by stallions on foals of their group or forced matings were observed during the study. Our study offers rare data showing that if male infanticide occurs in wild plains zebra, this should be rare, and has no important consequences for foal survival at the population level.

KEYWORDS: equids, group size, infant mortality, male turnover, sociality 


\section{INTRODUCTION}

Social dynamics can play a major role in shaping the population ecology and evolutionary trajectory of a species (Clutton-Brock, 2016). Interactions between conspecifics can directly affect their fitness: to the extreme, some individuals can kill or be killed, as for instance in several mammalian carnivores during territorial conflicts (Mech, 1994; Mosser \& Packer, 2009; Thompson, Marshall, Vitikainen, \& Cant, 2017). More commonly, individuals can affect the reproductive output of others via various social behaviours, for instance, by limiting access to resources (e.g. interference competition) or mates (e.g. intra-sexual competition), or, in contrast, by taking care of one's offspring (e.g. communal breeding) (Silk, 2007).

A classic example of such link between social dynamics and individuals' fitness is infanticide by males the killing of dependent offspring by an unrelated conspecific adult male - which is widespread, occurring in taxa as varied as fish, amphibians, birds, and mammals (Hausfater \& Hrdy, 1984; Lukas \& Huchard, 2014). Obviously, an infanticide decreases the reproductive output of the female whose offspring is killed. Conversely, the reproductive output of the infanticidal male is likely increased: the most commonly accepted hypothesis for the evolution of this behaviour, the 'sexual selection hypothesis', posits that an infanticidal male increases its mating opportunities by shortening the latency during which a female is unavailable to reproduce, either because of temporal infertility or behavioural rejection of mating attempts (Dixson, 2012; Hrdy, 1979; McNeilly, 1997).

The importance of infanticide by males, as a factor shaping population dynamics, remains controversial however. Previous works on rodents have shown that population growth rates can be dramatically reduced when the rate of male replacement is experimentally increased, probably because of an increased rate of infanticide, but infanticides were not directly observed (Andreassen \& Gundersen, 2006; Opperbeck, Ylönen, \& Klemme, 2012). Studies on bears and lions have suggested that the selective killing of reproductive males by human hunters could affect the dynamics of whole populations due to the increased rate of male turnovers and thereby infanticides (Loveridge, Hemson, Davidson, \& Macdonald, 2010; Swenson 
et al., 1997; Whitman, Starfield, Quadling, \& Packer, 2004). However, there is still only scarce evidence from unmanipulated populations that infanticide matters at the population-level, and further studies are required to consolidate our understanding of the contribution of infanticide to population dynamics.

Infanticides occur mainly in species which can breed year-round and where reproduction is monopolized by a few males (Lukas \& Huchard, 2014), and a number of equids such as feral horses (Equus ferus), Przewalski's horses (Equus ferus przewalskii), mountain zebras (Equus zebra), and plains zebras (Equus quagga), display such characteristics. These species form harems where a stallion (i.e. harem-male) is associated with several females and their dependent young, and can breed year round, traits that should have facilitated the evolution of infanticide. Males that do not hold a harem form loose bachelor groups and will eventually attempt to start a harem by 'abducting' young females, monopolizing dispersing young females or taking over a harem by replacing the stallion. In these harem-forming equids, infanticide by males is expected for several reasons (see references in Bartoš, Bartošová, \& Pluháček, 2019; Ebensperger, 1998; Palombit, 2015). First, infanticide can reduce the latency for the next breeding attempt of the female. For instance, in plains zebras, the latency after a birth for the next breeding attempt can be as short as a few weeks and as long as 15 months (Barnier, Grange, Ganswindt, Ncube, \& Duncan, 2012). If the costs of raising a foal influence the latency, then infanticide could potentially increase the stallion's reproductive success. Secondly, with the disappearance of her young, the female will not bear the costs of lactation anymore. This can lead her to have a better body condition and increases the chances that the next reproduction - with the infanticidal male - is successful. Finally, foals can be accidentally involved in fights and injured or killed, since newly established stallions usually exhibit high testosterone levels which, combined with the fact that mares may reject their mating attempts, can make for situations where the survival of foals is at risk.

Male infanticide following a stallion turnover (i.e. replacement of a stallion by a different male) has often been reported in equids, but mostly in small and domestic, captive or reintroduced populations (Camargue horses: Duncan, 1982; Przewalski's horses: Chen, Weng, Chao, Hu, \& Taya, 2008; Dorj \& Namkhai, 2013; Feh \& Munkhtuya, 2008; Kolter \& Zimmermann, 1988; Ryder \& Massena, 1988). In captive plains zebras, 
10 records of infanticidal attacks by males have been reported over 27 years of monitoring (Pluháček \& Bartoš, 2000, 2005; Pluháček, Bartoš, \& Víchová, 2006). These are all populations where natural sociality had been disrupted. Infanticide could also be common in captive and recently reintroduced equids not because it is adaptive, but because the behaviour results from increased aggressiveness due to social stress (C. Feh, pers.comm.). Penzhorn (1985) reported indirect evidence for infanticide in wild mountain zebras, but observations of infanticide in wild equids are scarce: Gray (2009) observed an attempt of infanticide by a mustang, but argued that it was exceptional. Infanticide has been seen only once in wild plains zebras (Ransom \& Kaczensky, 2016) but the relationships of the foal to the harem in which it occurred are unknown. Forced copulations following stallion turnovers occurred regularly in the mustangs studied by Berger (1983), leading him to suggest that feticide - the abortion of a fetus due to forced mating or sexual harassment by a conspecific adult male - might be adaptive in horses and other equids. The importance of such behaviour in equids remains controversial however (Kirkpatrick \& Turner, 1991). Overall, the current state of knowledge is unclear about whether infanticide is common or rare in equids, and whether it matters or not for the dynamics of their populations (as implicitly suggested in Grange et al., 2004).

Here we use a long term study of the behaviour and demography of a large wild population of plains zebras conducted since 2004 in Hwange National Park (HNP, Zimbabwe) where stallion turnovers were recorded and accurate data on pregnancy were obtained by hormone assays. This study offers a rare occasion to test for the occurrence of infanticide after stallion turnovers and assess the potential influence of these turnovers on foal survival in a wild equid.

Specifically, we test here the predictions that (1) the rate of stallion turnover increases with the number of reproductive females (i.e. subadult and adult females) in a harem, and (2) that foals in harems that experience, either as fetuses or soon after their birth, a stallion turnover have a lower survival probability than foals in harems where such event did not occur. 


\section{MATERIAL AND METHODS}

\section{Study species and site}

The study was conducted in the eastern section of HNP in Western Zimbabwe over an area covering ca. 2000 $\mathrm{km}^{2}\left(19^{\circ} 00^{\prime} \mathrm{S}, 26^{\circ} 30^{\prime} \mathrm{E}\right)$. The vegetation is dominantly bushy, characteristic of semiarid dystrophic savannas, but interspersed with patches of open grasslands (Chamaille-Jammes, Fritz, \& Murindagomo, 2006). The annual rainfall averages $600 \mathrm{~mm}$, with most rains falling between November and April, the rainy season (Chamaille-Jammes et al., 2006). Predation pressure is high as lions (Panthera leo) are abundant (i.e. around 3.5 individuals $100 \mathrm{~km}^{-2}$ ) (Loveridge et al., 2016), and leopards (P. pardus), cheetahs (Acinonyx jubatus), and spotted hyenas (Crocuta crocuta) are also present, all known to attack zebra foals. In the study area, plains zebra density fluctuated slightly around 1 individual km² (Chamaillé-Jammes, Valeix, Bourgarel, Murindagomo, \& Fritz, 2009; Grange et al., 2015) between 2004 and 2017, when we monitored the behaviour and fate of individual zebras.

Plains zebra populations are made of two basic social units: harem and bachelor groups (Estes \& Otte, 2012; Klingel, 1969). Non-territorial harems are composed of a stallion and most often several adult females, subadults of both sexes, and dependent offspring. Subadult and adult females are hereafter referred to as 'reproductive females'. In the study area, harem sizes range between 2 and 10 individuals (median: 5 individuals), and are positively correlated to the number of reproductive females in harems (Spearman rank correlation: $\left.r_{\mathrm{s}}=0.89, N=51, P<0.001\right)$. Males that are not stallions form all-male bachelor groups, which range between 1 and 19 individuals (median: 3 individuals), and sometimes attempt to take over a stallion's position. In harems, young males and females disperse when they are around 2 years old (y.o.): dispersing females join already existing harems or form a new group with a bachelor, and males join bachelor groups. Reproductive females may also change group, but this is rare: in this study, $92 \%$ of mares $(N=453)$ were still in the same harem after one year and $86 \%(N=342)$ after two years. Therefore, although we give harems the 
same ID code from one session to the next when at least $25 \%$ of the females are the same than at the previous session, usually over $90 \%$ of the females are seen together at the next session.

\section{Data collection}

Observations were made twice a year, approximately one month in the wet season (between February and April) and three weeks in the dry season (between July and September). These monitoring periods are hereafter referred to as 'sessions'. We focused on harems, and determined group composition and identified new individuals. Field experience and the data presented here (see Results) suggest that stallion turnovers are not frequent enough to make the discontinuous sampling problematic, as the likelihood of several turnovers occurring between two sessions is very low. The zebras were identified by their unique stripe patterns (Grange et al., 2015) and were categorized into four age-classes: foal, from birth to 1 y.o.; yearling, between 1 and 2 y.o.; subadult, between 2 and 4 y.o.; and adults, 4 y.o. and older. The age of previously unobserved young individuals was estimated using Penzhorn's criteria (Penzhorn, 1982) combined with photos of foals of known age in the Hwange population. We used suckling behaviour as criteria to determine motherhood (as in Barnier et al., 2012). Indeed, although the possibility for adoption and allosuckling cannot be fully discarded, these events are very rare in equids (Olléová, Pluháček, \& King, 2012; Pluháček, Bartošová, \& Bartoš, 2010; Topczewska, Krupa, Rogowska, \& Ohimor, 2018). In addition, we opportunistically collected dung samples from females ( $N=357$ from 90 mares); these were air-dried within $48 \mathrm{~h}$ after collection and stored at room temperature until analysis for immunoreactive 20-oxopregnane and estrogen metabolite concentrations (Barnier et al., 2012; Ncube et al., 2011). Hormone concentrations allowed females to be allocated to nonpregnant, mid-pregnancy ( 9 to 3 months to foaling) or late pregnancy ( 3 to 0 months to foaling) stages (Ncube et al., 2011). Thanks to this information, we knew that a foal had been born even when it died before we resighted the harem, or had been lost by abortion. We could therefore compare the survival probability of foals in their first year in harems with or without a stallion turnover, assuming that if the mother is observed, the detection probability of the foal if it is alive is 1 . Under this realistic assumption, the observation of a mare, previously detected pregnant, without her foal is reliable evidence that the foal had not survived, as foals are 
dependent on their mother until the age of about 1 year. More details about the demographic monitoring of this population can be found in Grange et al. (2015). Demographic data and data on hormone levels collected between 2008 and 2017 are used here, corresponding to 19 sessions (10 in the wet season and 9 in the dry season) over 10 years.

During these sessions, ad hoc observations of behaviour were made, including attacks, mating and foaling. Although we did not specifically keep track of observation time, we estimated that a minimum of 5400 hours were spent directly observing zebras between July 2004 when the study started, and the last session in October 2019.

\section{Data analysis}

We first tested whether the probability of stallion turnover increases with the number of reproductive females in a harem (analysis 1). Stallion turnover was considered to have occurred if a harem was seen during two consecutive sessions with a different stallion at each session. For this analysis, we did not use information when the resighting of a harem occurs more than a year later (i.e. when the harem was not seen in two consecutive sessions), as there was too much uncertainty about how the number of reproductive females had changed during this period. In total, we observed 30 turnovers, out of 232 possible occasions where it could have occurred (i.e. when a harem is seen during a session and reobserved within a year, regardless of the stallion identity). We fitted generalized linear mixed models with logit links and a binomial distribution for errors to test the relationship between the likelihood of having observed a stallion turnover (response variable, binary coded with 1 for turnover and 0 for no turnover) and the number of reproductive females in the harem at the first session. To account for the fact that turnovers are more likely to occur as time passes, we included an additive effect of the log-transformed number of days between the two sessions. We also included the identity of the stallion and the identity of the harem as random effects on the intercept to account for the fact that stallions and harem females could differ in their ability to repel (for stallions) or willingness to accept (for females) an external male. 
We also investigated whether stallion turnover affected the survival probability of foals (analysis 2), using the data obtained from the hormone analyses conducted on the dung samples. We focused on mares detected pregnant through hormone analyses $(N=29$ in late pregnancy and $N=71$ in mid-pregnancy) and compared the probability of reobserving them with a foal at the next session when the stallion was replaced between the date of dung sampling and the date of the first resighting of the mare at the next session, and when a stallion turnover did not occur. Females detected in mid-pregnancy are between 9 and 3 months to the foaling date, so observing them without a foal at the next session could indicate that the foal had been aborted or died, but it is also possible that the foal was not yet born. However, this possible bias is independent of whether or not a stallion turnover occurred and will therefore not affect our results. Focusing only on females detected in mid-pregnancy $(N=89)$, we also tested the effect of stallion turnover on the probability of seeing a foal two sessions later (rather than at the next session). As the duration over which survival was estimated was greater, this analysis was more likely to be affected by other sources of mortality, and we consider it less robust, but note that it provided qualitatively similar results (Appendix Tables A1-A2, Fig. A1). We sometimes obtained two dung samples in the same pregnancy $(N=25)$, and if we did and the female was in late pregnancy it has been included in the analysis of late-pregnant females. In all cases the second sample also identified the female as pregnant (i.e. no abortion was observed). We tested the effect of stallion turnover on the probability of observing a foal at the next session (coded $1=$ mare re-observed with a foal, $0=$ mare re-observed without a foal) by fitting generalized linear mixed models with logit links and binomial distributions for errors. Explanatory variables included: a binary variable coding for whether stallion turnover had occurred; the logtransformed number of days between the date of dung sampling and the date of first resighting of the mare, to control for the expected negative effect of the time between the date of dung sampling and the date of first resighting of the mare on foal survival (i.e. survival probability decreases as time passes); age of the mare, to account for its many potential positive effects on pregnancy success (e.g. Bartoš, Bartošová, \& Pluháček, 2015; Bartoš, Bartošová, Pluháček, \& Šindelářová, 2011) and foal survival (e.g. Cameron, Linklater, Stafford, \& Minot, 2000); and season, to account for the potential influence of seasonal changes in forage quality and possibly predation risk, with the hypothesis that foal survival should be lower in the dry season: forage quality is lower, 
zebras remain near the few remaining waterholes that are also focus areas for hunting lions, and zebras' strategy to reduce this risk might be costly (see Courbin et al., 2019). We also included the identity of the mare as a random effect nested within a harem identity random effect, as we had repeated measures on the same individuals. More complex model structures including random effects for sessions or years to account for temporal autocorrelations led to overfitting.

For both analysis 1 and 2, we first fitted and reported full models, i.e. models integrating the explanatory variables presented above. The inclusion of the random effects led to convergence issues when models were fitted with a frequentist framework, and we therefore fitted models in a Bayesian framework using Stan (Carpenter et al., 2017) accessed using the package brms v. 2.13 .5 (Bürkner, 2017) in R v. 3.6 .2 (R Core Team, 2019). Bayesian analysis is characterized by (i) the use of prior distribution for model parameters: here, as commonly done, we used non-informative priors and checked that different priors led to the same conclusions; (ii) some stochasticity in the estimation process linked to the use of Monte-Carlo simulations: here, as often recommended, we ran four chains with 4000 iterations each. We confirmed convergence and quality of fit of the models using the criteria recommended for Bayesian analysis (Conn, Johnson, Williams, Melin, \& Hooten, 2018): visual inspection of trace plot, Rhat $<1$, effective sample size $>0.5 *$ post-warmup samples, posterior predictive checks. See McElreath (2020) for accessible additional information on Bayesian modeling. We based our assessment of the strength of the relationship between explanatory variables and response variables on the model mean posterior estimates and their $90 \%$ and $95 \%$ credible intervals. We also compared the predictive accuracy of models with and without the explanatory variable of interest. We did so using the Widely Applicable Information Criterion (also known as Watanabe-Akaike Information Criterion, hereafter WAIC), which is a generalized version of the AIC that is commonly used in Bayesian modelling as it estimates the effective number of parameters from posterior distributions (McElreath, 2020; Watanabe, 2010). This is usually important in models with random effects, as a priori determination of the number of parameters in this context is not clear. As with the AIC, the model with the lowest WAIC (hereafter 'top' model) has the best predictive accuracy. The standard error of the WAIC is obtained thanks to the use of the Monte-Carlo 
simulations, but more importantly, we can also obtain an estimation of the standard error of the difference in WAIC between a model of interest and the 'top' model. This allows understanding whether the WAIC of two models differ significantly. Additionally, we computed for each model its Akaike weight that, as for the AIC, can be interpreted as the probability that the model will make the best predictions, amongst the models tested. However, as with the AIC, one should keep in mind that when nested models achieve similar predictive accuracy, the explanatory variables present in the more complex models should be considered non-informative and not considered to have an effect (Arnold, 2010; Leroux, 2019).

\section{RESULTS}

Based on the model parameters, the probability that a stallion turnover occurred between two sessions increased with the time separating the two sessions and the number of reproductive females in harems (Table 1), varying on average from 0.03 to 0.43 for harems having from 1 to 5 reproductive females (Fig. 1). Both variables were critical to predict the likelihood of observing a turnover (compare WAIC weights of models in Appendix Table A3). In particular, note that the model only accounting for time between sessions but not accounting for the number of females (model 3) had virtually no chance to make better predictions than the model accounting for it (model 1).

Over the $>5400$ hours of monitoring, we never witnessed an infanticide, or even a stallion attacking a foal. Such behaviour was also never reported to us by other researchers or tourist guides working in the area. Based on the model parameters, the probability of observing a foal at the next session did not differ between situations when a stallion turnover occurred and those when it did not (Table 2, Fig. 2). This was also supported by the fact that accounting for turnovers into the models did not make these models more likely to predict whether a foal would be observed or not than models not accounting for turnovers (compare WAIC weights in Appendix Table A4). 
The analysis of data from females observed mid-pregnant and resighted two sessions later also supported a lack of relationship between the probability of foal survival and whether or not the stallion was replaced between the two sessions (Appendix Tables A1-A2). We note however that the estimated difference between turnover and no-turnover situations was greater, with a tendency for the probability of observing a foal two sessions later to be lower when the stallion had changed (Appendix Fig. A1).

\section{DISCUSSION}

This study shows that the frequency of stallion turnover increases with increasing number of reproductive females in harems, therefore supporting our prediction. We did not however detect a significant reduction in foal survival after a takeover, and now discuss the various insights brought by our work.

\section{Higher rate of stallion turnovers in larger female groups}

As predicted, the frequency of stallion turnovers increases with the number of reproductive females in a harem. Similar results have been found in other species, mainly in non-human primates (red howlers: Crockett \& Janson, 2000; colobus monkeys: Teichroeb et al. 2012; Thomas's langurs: Steenbeek \& Van Schaik, 2001; geladas: Dunbar 1984). To our knowledge, this is the first demonstration that this effect of group size holds in equids. Larger groups may be more attractive for bachelor males, the presence of many females increasing their chance of siring their own offspring following harem takeover. However, females are not passive resources and their choice, although not well understood yet, may be important in accepting a new stallion and in shaping the benefits gained by the incoming male in terms of reproductive success (Smuts \& Smuts, 1993). For instance, there are some observations of female wild horses that managed to prevent forced copulations by kicking and escaping from the newly established male (Berger, 1986). Another possibility to explain the positive relationship between rate of male turnover and female group size is that larger harems with many females may be more difficult for the stallion to defend against intruding males, therefore increasing the likelihood of being taken over by a bachelor male. For instance, in wild horses, the energy invested by stallions 
in the defense of their harems increases with harem size, but the energy cost per female defended was reduced in larger harems, which could make them more attractive to bachelors (Berger, 1986). Finally, harems composed of many reproductive females provide a more heterogeneous mating opportunity for the incoming male, the more numerous these females are, the greater the chance that some of them are not pregnant and available for reproduction.

In conclusion to this section, harem takeovers are frequent in this population, and larger females groups are more likely to experience stallion turnovers.

\section{Lack of evidence for male infanticide following harem takeover in the wild}

In captive plains zebras, Pluháček and colleagues have regularly observed forced copulations and attacks on foals (Pluháček \& Bartoš, 2005; Pluháček et al., 2006). In contrast, in our study population, no forced mating or infanticide event, nor even an attack of a stallion towards a foal, has been seen in more than 15 years of observations, with over 5400 hours spent watching the animals. We found no evidence to suggest that infanticide could specifically occur at times when no observations are conducted (e.g. night). We additionally showed here that stallion turnovers had no statistically apparent effect on foal survival - which should be case should infanticide occur. We however acknowledge that sample sizes in these analyses are small, and further studies will be welcomed to ascertain this conclusion. We also note that other processes, unrelated to infanticide, might lead to reduced foal survival after stallion turnovers: young foals can make inappropriate responses and get killed by accident in situations where stallions and other individuals are involved in attacks and chases as often happens during takeovers. This has been reported in horses for instance (C. Feh \& P. Duncan, pers. obs.; Duncan, 1992). The new male may be less attentive to protecting foals from predators. Overall, our study suggests that, in this population, infanticide either does not occur or is rare. This is consistent with Pluháček \& Bartoš (2005) report that they did not find any record of infanticide in the wild in plains zebras (but see Ransom \& Kaczensky (2016) for one anecdotal observation). 
Based on much more limited data, Klingel (1967) found a similar result in the Tanzania's Ngorongoro Crater population, where no infanticide was observed, although several takeovers of harems composed of pregnant females and young foals were recorded. Jaworska et al. (2020) reported similar findings in a population of semi-feral Konik polski horses (E. caballus) where, over 31 years of monitoring, infanticide by males was never observed and stallion turnovers had no significant effects on female reproductive success. These results contrast with studies of other harem-forming species where male infanticide following haremmale turnovers has been found (e.g. in lions: Bertram, 1975; Packer et al., 1988; Packer \& Pusey, 1983; blue monkeys: Butynski, 1982, 1990). In wild horses, female reproductive success to the next parturition season was significantly lower in unstable groups that experienced a stallion turnover compared to stable groups (Berger, 1986), and, in reintroduced Przewalski's horses, $9 \%$ of all foal mortality reported was attributed to infanticide by a newly established stallion (53 of 580 foals between 1994 and 2019) (Dorj \& Namkhai, 2013; U. Dorj, pers.comm.).

Although our results do not provide evidence for infanticide in wild plains zebra, this behaviour has been observed for this species in captivity (Pluháček et al., 2006) and the social and mating system of plain zebras should favor the emergence of infanticide behaviour (Lukas \& Huchard, 2014). This raises the question of why the situation is so different in the wild: a possible explanation is that conditions in captivity and recent reintroduction may alter the behaviour of the animals and elevate the frequency of infanticide events, the 'social pathology hypothesis' (discussed by Feh \& Munkhtuya, 2008; Van Schaik \& Janson, 2000). Leaving this hypothesis aside, we see several possible hypotheses for why infanticide would not occur or be rare in the wild in plains zebras, although the species presents traits that should favour this behaviour: (1) the killing of a dependent offspring benefits infanticidal males only if it improves their reproductive success by shortening the interbirth interval of the mother, and this may not be the case in plains zebras. In Przewalski's horses, Feh \& Munkhtuya (2008) found that infanticide did not reduce interbirth intervals and that mares whose foals had been attacked avoided affiliating with the infanticidal male later on, therefore contesting the 'sexual selection hypothesis' and calling into question the necessity for the incoming male to kill a dependent young in such 
condition. However, infanticide may still improve the reproductive success of infanticidal males by stopping lactation and improving the mare's body condition and subsequent pregnancy success. Despite this potential benefit, males do not appear to commit infanticide. This is unexpected, especially at a site like Hwange where a male's reproductive period may be limited by both high intra-male competition and high predation risk, as we would expect any possibility increasing their chance to reproduce to be used by males. Therefore, either these purported benefits do not exist, or, we tentatively suggest, it could be that the high foal loses due to predation reduce the need for males to resort to infanticide; (2) female plains zebras may have developed counterstrategies such as female sociality and/or maternal aggression and protectiveness, allowing them to protect their progeny against intruders. For instance, in feral horses, higher maternal protection when several males are present in a group and higher protection towards foals that are not sired by the stallion have been reported (Cameron, Linklater, Stafford, \& Minot, 2003; Gray, 2009; Watts et al., 2020). In captive mountain zebra, a female was observed to actively defend her foal against an infanticidal male (Joubert, 1972), and similarly, in Przewalski's horses, all females whose foal was attacked by an infanticidal male strongly defended their foal, and in one case, the mare was helped by her half-sister (Feh \& Munkhtuya, 2008). In wild horses, females have been shown to cooperate and help each other at aggressively repelling newly established males that coerce females to mate following group takeover (Berger, 1986). These strategies are likely to exist in plains zebra too, although it has never been documented in this species; (3) females could have evolved means to proactively terminate the pregnancy to avoid energy loss if the likelihood of losing the foal due to infanticide was high after a stallion turnover (Bartoš, Dušek, Bartošová, Pluháček, \& Putman, 2020). In such case, which is known to occur in plains zebras in captivity (Pluháček \& Bartoš, 2000, 2005), infanticide could be rarely observed, although it would exist as a behaviour that could be expressed by a new male in presence of a foal. Demonstrations of these effects in the wild remain scarce (Bartoš et al., 2020). If this applied to our case, stallion turnovers would however lead to reduced offspring survival when offspring survival is estimated from pregnancy stage, as in our study. We did not find evidence of this in our limited dataset, but note that the contrast in offspring survival between turnover and no-turnover situations was greater when survival was assessed from mid-pregnancy onward. Therefore, testing the existence of pregnancy termination in wild plains 
zebras could be an interesting avenue of research, as it complexifies the evolutionary perspective needed to understand how social events could have demographic consequences.

\section{Demographic impact of stallion turnovers}

One of our key objectives was to test whether accounting for stallion turnovers was important to understand and analyze zebra population dynamics. Grange et al. $(2004,2015)$ established, using demographic analysis of zebra populations, that foal survival was generally low. They however also stated (Grange et al., 2004) that the processes involved in foal mortality had not been fully elucidated, and questioned the relative contribution of predation and social factors such as infanticide. Our study brings some insights: irrespectively of whether stallion turnovers can sometimes lead to infanticide or not, their demographic effect at the population level is likely limited, and other factors are more likely to explain the overall low foal survival observed.

\section{CONCLUSION}

In conclusion, this study offers the first demonstration for an equid that male turnover rates are high in the wild, and increase with female group size. Based on work in captivity, plains zebra is commonly cited as an example of species in which male infanticide occurs. However, our results suggest that caution should be applied when hypothesizing that infanticide occurs in the wild - we found no evidence of this, although we cannot conclude that it never occurs. We can however conclude that, in the studied population, an effect of stallion turnovers on foal survival is not readily apparent. Additionally, we suggest that high predation risk, which strongly reduces foal survival, may reduce the relative fitness gains of males committing infanticide vs. those who do not, therefore affecting its evolution in the wild. More generally, our study shows that demographic signals of a priori important social processes should be investigated closely rather than assumed. 


\section{REFERENCES}

Andreassen, H. P., \& Gundersen, G. (2006). Male turnover reduces population growth: an enclosure experiment on voles. Ecology, 87(1), 88-94. https://doi.org/10.1890/04-1574

Arnold, T. W. (2010). Uninformative Parameters and Model Selection Using Akaike's Information Criterion. Journal of Wildlife Management, 74(6), 1175-1178. https://doi.org/10.2193/2009-367

Barnier, F., Grange, S., Ganswindt, A., Ncube, H., \& Duncan, P. (2012). Inter-birth interval in zebras is longer following the birth of male foals than after female foals. Acta Oecologica, 42, 11-15. https://doi.org/10.1016/j.actao.2011.11.007

Bartoš, L., Bartošová, J., \& Pluháček, J. (2015). Pregnancy disruption in artificially inseminated domestic horse mares as a counterstrategy against potential infanticide. Journal of Animal Science, 93(11), 5465-5468. https://doi.org/10.2527/JAS.2015-9384

Bartoš, L., Bartošová, J., \& Pluháček, J. (2019). Behavioral factors affecting reproduction in domestic horses sociobiological approach. In D. L. Pusta (Ed.), Animal Genetics (pp. 27-44). London, United Kingdom: InTechOpen. https://doi.org/10.5772/intechopen.76580

Bartoš, L., Bartošová, J., Pluháček, J., \& Šindelářová, J. (2011). Promiscuous behaviour disrupts pregnancy block in domestic horse mares. Behavioral Ecology and Sociobiology, 65(8), 1567-1572. https://doi.org/10.1007/s00265-011-1166-6

Bartoš, L., Dušek, A., Bartošová, J., Pluháček, J., \& Putman, R. (2020). How to escape male infanticide: mechanisms for avoiding or terminating pregnancy in mammals. Mammal Review, mam.12219. https://doi.org/10.1111/mam.12219

Berger, J. (1983). Induced abortion and social factors in wild horses. Nature, 303(5912), 59-61. https://doi.org/10.1038/303059a0 
Berger, J. (1986). Wild horses of the Great Basin : social competition and population size. University of Chicago Press.

Bertram, B. C. R. (1975). Social factors influencing reproduction in wild lions. Journal of Zoology, 177(4), 463482. https://doi.org/10.1111/J.1469-7998.1975.TB02246.X@10.1111/(ISSN)1469-7998.JZO50

Bürkner, P. C. (2017). brms: An R package for Bayesian multilevel models using Stan. Journal of Statistical Software, 80(1), 1-28. https://doi.org/10.18637/jss.v080.i01

Butynski, T. M. (1982). Harem-male replacement and infanticide in the blue monkey (Cercopithecus mitus stuhlmanni) in the Kibale Forest, Uganda. American Journal of Primatology, 3(1-4), 1-22. https://doi.org/10.1002/ajp.1350030102

Butynski, T. M. (1990). Comparative Ecology of Blue Monkeys (Cercopithecus Mitis) in High- and Low-Density Subpopulations. Ecological Monographs, 60(1), 1-26. https://doi.org/10.2307/1943024

Cameron, E. Z., Linklater, W. L., Stafford, K. J., \& Minot, E. O. (2000). Aging and improving reproductive success in horses: Declining residual reproductive value or just older and wiser? Behavioral Ecology and Sociobiology, 47(4), 243-249. https://doi.org/10.1007/s002650050661

Cameron, E. Z., Linklater, W. L., Stafford, K. J., \& Minot, E. O. (2003). Social grouping and maternal behaviour in feral horses (Equus caballus): The influence of males on maternal protectiveness. Behavioral Ecology and Sociobiology, 53(2), 92-101. https://doi.org/10.1007/s00265-002-0556-1

Carpenter, B., Gelman, A., Hoffman, M. D., Lee, D., Goodrich, B., Betancourt, M., ... Riddell, A. (2017). Stan: A probabilistic programming language. Journal of Statistical Software, 76(1), 1-32. https://doi.org/10.18637/jss.v076.i01

Chamaillé-Jammes, S., Valeix, M., Bourgarel, M., Murindagomo, F., \& Fritz, H. (2009). Seasonal density estimates of common large herbivores in Hwange National Park, Zimbabwe. African Journal of Ecology, 
47(4), 804-808. https://doi.org/10.1111/j.1365-2028.2009.01077.x

Chamaille-Jammes, S., Fritz, H., \& Murindagomo, F. (2006). Spatial patterns of the NDVI-rainfall relationship at the seasonal and interannual time scales in an African savanna. International Journal of Remote Sensing, 27(23), 5185-5200. https://doi.org/10.1080/01431160600702392

Chen, J., Weng, Q., Chao, J., Hu, D., \& Taya, K. (2008). Reproduction and development of the released Przewalski's horses (Equus przewalskii) in Xinjiang, China. Journal of Equine Science, 19(1), 1-7. https://doi.org/10.1294/jes.19.1

Clutton-Brock, T. H. (2016). Mammal Societies. Chichester, West Sussex, UK: John Wiley \& Sons.

Conn, P. B., Johnson, D. S., Williams, P. J., Melin, S. R., \& Hooten, M. B. (2018). A guide to Bayesian model checking for ecologists. Ecological Monographs, 88(4), 526-542. https://doi.org/10.1002/ecm.1314

Courbin, N., Loveridge, A. J., Fritz, H., Macdonald, D. W., Patin, R., Valeix, M., \& Chamaillé-Jammes, S. (2019). Zebra diel migrations reduce encounter risk with lions at night. Journal of Animal Ecology, 88(1), 92-101. https://doi.org/10.1111/1365-2656.12910

Crockett, C. M., \& Janson, C. H. (2000). Infanticide in red howlers: female group size, male membership, and a possible link to folivory. In Infanticide by Males and its Implications (pp. 75-98). Cambridge University Press. https://doi.org/10.1017/CBO9780511542312.006

Dixson, A. (2012). Primate sexuality. The International Encyclopedia of Human Sexuality, 861-1042.

Dorj, U., \& Namkhai, B. (2013). Reproduction and mortality of re-introduced Przewalski's horse Equus przewalskii in Hustai National Park, Mongolia. Journal of Life Sciences, 7(6), 623-629.

Dunbar, R. (1984). Reproductive decisions: an economic analysis of gelada baboon social strategies. Princeton University Press. 
Duncan, P. (1982). Foal killing by stallions. Applied Animal Ethology, 8(6), 567-570.

https://doi.org/10.1016/0304-3762(82)90221-8

Duncan, P. (1992). Horses and Grasses: The Nutritional Ecology of Equids and Their Impact on the Camargue. Springer New York.

Ebensperger, L. A. (1998). Strategies and counterstrategies to infanticide in mammals. Biological Reviews, 73(3), 321-346. https://doi.org/10.1111/j.1469-185X.1998.tb00034.x

Estes, R., \& Otte, D. (2012). The behavior guide to African mammals : including hoofed mammals, carnivores, primates. University of California Press.

Feh, C., \& Munkhtuya, B. (2008). Male infanticide and paternity analyses in a socially natural herd of Przewalski's horses: Sexual selection? Behavioural Processes, 78(3), 335-339. https://doi.org/10.1016/j.beproc.2007.12.009

Grange, S., Barnier, F., Duncan, P., Gaillard, J. M., Valeix, M., Ncube, H., ... Fritz, H. (2015). Demography of plains zebras (Equus quagga) under heavy predation. Population Ecology, 57(1), 201-214. https://doi.org/10.1007/s10144-014-0469-7

Grange, S., Duncan, P., Gaillard, J.-M., Sinclair, A. R. E., Gogan, P. J. P., Packer, C., ... East, M. (2004). What limits the Serengeti zebra population? Oecologia, 140(3), 523-532. https://doi.org/10.1007/s00442-004-1567-6

Gray, M. E. (2009). An infanticide attempt by a free-roaming feral stallion (Equus caballus). Biology Letters, 5(1), 23-25. https://doi.org/10.1098/rsbl.2008.0571

Hausfater, G., \& Hrdy, S. B. (1984). Infanticide : comparative and evolutionary perspectives. Aldine Pub. Co.

Hrdy, S. B. (1979). Infanticide among animals: A review, classification, and examination of the implications for the reproductive strategies of females. Ethology and Sociobiology, 1(1), 13-40. https://doi.org/10.1016/0162-3095(79)90004-9 
Jaworska, J., Jaworski, Z., McDonnell, S. M., \& Górecka-Bruzda, A. (2020). Harem stallion changes are not associated with diminished reproductive performance of females in semi-feral Konik polski horses (Equus caballus). Theriogenology. https://doi.org/10.1016/j.theriogenology.2020.03.033

Joubert, E. (1972). The social organization and associated behaviour in the Hartmann zebra Equus zebra hartmannae. Madoqua, 1972(Series 1 Issue 6), 17-56.

Kirkpatrick, J. F., \& Turner, J. W. (1991). Changes in herd stallions among feral horse bands and the absence of forced copulation and induced abortion. Behavioral Ecology and Sociobiology, 29(3), 217-219. https://doi.org/10.1007/BF00166404

Klingel, H. (1967). Soziale Organisation und Verhalten freilebender Steppenzebras. Zeitschrift Für Tierpsychologie, 24(5), 580-624. https://doi.org/10.1111/j.1439-0310.1967.tb00807.x

Klingel, H. (1969). The Social Organisation and Population Ecology of the Plains Zebra (Equus Quagga). Zoologica Africana, 4(2), 249-263. https://doi.org/10.1080/00445096.1969.11447374

Kolter, L., \& Zimmermann, W. (1988). Social behaviour of Przewalski horses (Equus p. przewalskii) in the Cologne Zoo and its consequences for management and housing. Applied Animal Behaviour Science, 21(1-2), 117-145. https://doi.org/10.1016/0168-1591(88)90104-9

Leroux, S. J. (2019). On the prevalence of uninformative parameters in statistical models applying model selection in applied ecology. PLoS One, 14(2), e0206711.

Loveridge, A. J., Hemson, G., Davidson, Z., \& Macdonald, D. (2010). African lions on the edge: Reserve boundaries as "attractive sinks." Biology and Conservation of Wild Felids, 283, 283-304.

Loveridge, A. J., Valeix, M., Chapron, G., Davidson, Z., Mtare, G., \& Macdonald, D. W. (2016). Conservation of large predator populations: Demographic and spatial responses of African lions to the intensity of trophy hunting. Biological Conservation, 204, 247-254. https://doi.org/10.1016/j.biocon.2016.10.024 
Lukas, D., \& Huchard, E. (2014). The evolution of infanticide by males in mammalian societies. Science, 346(6211), 841-844. https://doi.org/10.1126/science.1257226

McElreath, R. (2020). Statistical rethinking: A Bayesian course with examples in R and Stan. CRC press.

McNeilly, A. S. (1997). Lactation and fertility. Journal of Mammary Gland Biology and Neoplasia, 2(3), $291-298$. https://doi.org/10.1023/A:1026340606252

Mech, L. D. (1994). Buffer zones of territories of gray wolves as regions of intraspecific strife. Journal of Mammalogy, 75(1), 199-202. https://doi.org/10.2307/1382251

Mosser, A., \& Packer, C. (2009). Group territoriality and the benefits of sociality in the African lion, Panthera leo. Animal Behaviour, 78(2), 359-370. https://doi.org/10.1016/j.anbehav.2009.04.024

Ncube, H., Duncan, P., Grange, S., Cameron, E. Z., Barnier, F., \& Ganswindt, A. (2011). Pattern of faecal 20oxopregnane and oestrogen concentrations during pregnancy in wild plains zebra mares. General and Comparative Endocrinology, 172(3), 358-362. https://doi.org/10.1016/J.YGCEN.2011.03.027

Olléová, M., Pluháček, J., \& King, S. R. B. (2012). Effect of social system on allosuckling and adoption in zebras. Journal of Zoology, 288(2), 127-134. https://doi.org/10.1111/j.1469-7998.2012.00930.x

Opperbeck, A., Ylönen, H., \& Klemme, I. (2012). Infanticide and population growth in the bank vole (Myodes glareolus): the effect of male turnover and density. Ethology, 118(2), 178-186. https://doi.org/10.1111/j.1439-0310.2011.01998.x

Packer, C., Herbst, L., Pusey, A. E., Bygott, J. D., Hanby, J. P., Cairns, S. J., \& Borgerhoff-Mulder, M. (1988). Reproductive success of lions. In T. H. Clutton-Brock (Ed.), Reproductive success: Studies of Individual Variation in Contrasting Breeding Systems (pp. 363-383). University of Chicago Press.

Packer, C., \& Pusey, A. E. (1983). Adaptations of Female Lions to Infanticide by Incoming Males. The American Naturalist, 121, 716-728. https://doi.org/10.2307/2460874 
Palombit, R. A. (2015). Infanticide as sexual conflict: Coevolution of male strategies and female counterstrategies. Cold Spring Harbor Perspectives in Biology, 7(6), 1-31. https://doi.org/10.1101/cshperspect.a017640

Penzhorn, B. L. (1982). Age determination in Cape Mountain Zebras Equus Zebra Zebra in the Mountain Zebra National Park. Koedoe, 25(1), 89-102. https://doi.org/10.4102/koedoe.v25i1.607

Penzhorn, B. L. (1985). Reproductive characteristics of a free-ranging population of Cape Mountain zebras (Equus zebra zebra). Journal of Reproduction and Fertility, 73(1), 51-57.

Pluháček, J., \& Bartoš, L. (2000). Male infanticide in captive plains zebra, Equus burchelli. Animal Behaviour, 59(4), 689-694. https://doi.org/10.1006/ANBE.1999.1371

Pluháček, J., \& Bartoš, L. (2005). Further evidence for male infanticide and feticide in captive plains zebra, Equus burchelli. Folia Zoologica, 54(3), 258-262. https://doi.org/10.1006/anbe.1999.1371

Pluháček, J., Bartoš, L., \& Víchová, J. (2006). Variation in Incidence of Male Infanticide within Subspecies of Plains Zebra (Equus burchelli). Journal of Mammalogy, 87(1), 35-40. https://doi.org/10.1644/05-MAMMA-126R2.1

Pluháček, J., Bartošová, J., \& Bartoš, L. (2010). Suckling behavior in captive plains zebra (Equus burchellii): Sex differences in foal behavior. Journal of Animal Science, 88(1), 131-136. https://doi.org/10.2527/jas.20091982

R Core Team. (2019). R: A Language and Environment for Statistical Computing. Vienna, Austria: R Foundation for Statistical Computing.

Ransom, J. I., \& Kaczensky, P. (2016). Wild Equids: Ecology, Management, and Conservation. Johns Hopkins University Press.

Ryder, O. A., \& Massena, R. (1988). A case of male infanticide in Equus przewalskii. Applied Animal Behaviour 
Science, 21(1-2), 187-190. https://doi.org/10.1016/0168-1591(88)90107-4

Silk, J. B. (2007). The adaptive value of sociality in mammalian groups. Philosophical Transactions of the Royal Society B: Biological Sciences, 362(1480), 539-559. https://doi.org/10.1098/rstb.2006.1994

Smuts, B. B., \& Smuts, R. w. (1993). Male Aggression and Sexual Coercion of Females in Nonhuman Primates and Other Mammals: Evidence and Theoretical Implications. In Advances in the Study of Behavior (Vol. 22, pp. 1-63). https://doi.org/10.1016/S0065-3454(08)60404-0

Steenbeek, R., \& Van Schaik, C. P. (2001). Competition and group size in Thomas's langurs (Presbytis thomasi): The folivore paradox revisited. Behavioral Ecology and Sociobiology, 49(2-3), 100-110. https://doi.org/10.1007/s002650000286

Swenson, J. E., Sandegren, F., Söderberg, A., Bjärvall, A., Franzén, R., \& Wabakken, P. (1997). Infanticide caused by hunting of male bears. Nature, 386(6624), 450-451. https://doi.org/10.1038/386450a0

Teichroeb, J. A., Wikberg, E. C., Bădescu, I., Macdonald, L. J., \& Sicotte, P. (2012). Infanticide risk and male quality influence optimal group composition for Colobus vellerosus. Behavioral Ecology, 23(6), 13481359.

Thompson, F. J., Marshall, H. H., Vitikainen, E. I. K., \& Cant, M. A. (2017). Causes and consequences of intergroup conflict in cooperative banded mongooses. Animal Behaviour, 126, 31-40. https://doi.org/10.1016/j.anbehav.2017.01.017

Topczewska, J., Krupa, W., Rogowska, A., \& Ohimor, J. (2018). The Case of Communal Rearing of a Foal by Two Mares (Equus caballus). Journal of Equine Veterinary Science, 67, 99-101. https://doi.org/10.1016/j.jevs.2018.03.016

Van Schaik, C. P., \& Janson, C. H. (Eds.). (2000). Infanticide by males and its implications. Cambridge: Cambridge University Press. 
Watanabe, S. (2010). Asymptotic equivalence of Bayes cross validation and widely applicable information criterion in singular learning theory. Journal of Machine Learning Research, 11, 3571-3594.

Watts, E. T., Johnson, C. N., Carver, S., Butler, C., Harvey, A. M., \& Cameron, E. Z. (2020). Maternal protectiveness in feral horses: responses to intraspecific and interspecific sources of risk. Animal Behaviour, 159, 1-11. https://doi.org/10.1016/j.anbehav.2019.10.018

Whitman, K., Starfield, A. M., Quadling, H. S., \& Packer, C. (2004). Sustainable trophy hunting of African lions. Nature, 428(6979), 175-178. https://doi.org/10.1038/nature02395 


\section{ACKNOWLEDGMENTS}

We thank the Director General of the Zimbabwe Parks and Wildlife Management Authority for providing the opportunity to carry out this research. We acknowledge the support of the 'Zone Atelier' program of the CNRS. We also thank the many people - too numerous to be named here - involved in this project over the years. We are particularly grateful to Claudia Feh for discussions on the conceptual framework which were more than useful. This work was supported by the French 'Agence Nationale de la Recherche' (grants SAVARID ANR-11CEPS-003 and LANDTHIRST ANR-16-CE02-0001-01) and a PhD fellowship from 'Université de Montpellier' to C.V. 
Table 1. Coefficients of the mixed model investigating the effect of the number of reproductive females in a harem on the probability of stallion turnover between two sessions $\left(\operatorname{Pr}_{(\text {turnover) }}\right)$.

\begin{tabular}{llccc}
\hline Effect type & Coefficient & Estimate & $90 \%$ Crl & $95 \%$ Crl \\
\hline Group-level ('random') effects & ID(Stallion) & 1.60 & $0.57-2.86$ & $0.39-3.19$ \\
& ID(Harem) & 0.55 & $0.04-1.34$ & $0.02-1.57$ \\
Population-level ('fixed') effects & Intercept & -15.15 & $-23.02--8.42$ & $-25.00--7.21$ \\
& $\mathrm{~N}_{\text {fem }}$ & 1.25 & $0.68-1.91$ & $0.60-2.05$ \\
& $\log$ (Days) & 1.79 & $0.65-3.09$ & $0.43-3.38$ \\
\hline
\end{tabular}

Variables are: the number of reproductive females $\left(\mathrm{N}_{\mathrm{fem}}\right)$ and the log-transformed number of days between the two sessions ( $\log ($ Days $))$ as fixed effects, and identities of the stallion (ID(Stallion)) and of the harem (ID(Harem)) as random effects. The estimates and their $90 \%$ and $95 \%$ credible intervals $(\mathrm{Crl})$ are shown. 
Table 2. Coefficients of the mixed model investigating the effect of stallion turnover on the probability of observing a foal at the next session $\left(\operatorname{Pr}_{\text {(obs next session) })}\right)$.

\begin{tabular}{llccc}
\hline Effect type & Coefficient & Estimate & $90 \%$ Crl & $95 \%$ Crl \\
\hline Group-level ('random') effects & ID(Harem) & 0.88 & $0.09-1.98$ & $0.04-2.24$ \\
& ID(Harem):ID(Mare) & 0.95 & $0.08-2.28$ & $0.04-2.62$ \\
& Intercept & 3.49 & $-7.85-14.77$ & $-10.00-17.07$ \\
Population-level ('fixed') effects & Turnover_true & -0.41 & $-1.70-0.86$ & $-1.95-1.12$ \\
& Iog(Days) & -1.26 & $-3.54--0.94$ & $-4.06-1.39$ \\
& Age(mare) & 0.02 & $0.00-0.04$ & $0.00-0.04$ \\
& Season_wet & 1.18 & $0.21-2.22$ & $0.03-2.44$ \\
\hline
\end{tabular}

Variables are: stallion turnover (Turnover, binary: no turnover (false), turnover (true)), the log-transformed number of days between the date of dung sampling and the date of first resighting of the mare $(\log ($ Days $))$, age of the mare in months when first resighted (Age(mare)), and season (Season, dry, wet) as fixed effects; and identities of the mare (ID(Mare)) and the harem (ID(Harem)) as nested random effects. The estimates and their $90 \%$ and $95 \%$ credible intervals $(\mathrm{Crl})$ are shown. 
Table A1. Coefficients of the mixed model investigating the effect of stallion turnover on the probability of

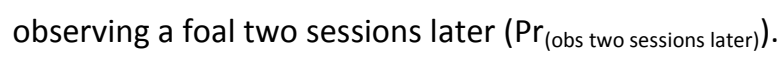

\begin{tabular}{llccc}
\hline Effect type & Coefficient & Estimate & $90 \% \mathrm{Crl}$ & $95 \% \mathrm{Crl}$ \\
\hline Group-level ('random') effects & ID(Harem) & 1.02 & $0.12-2.18$ & $0.05-2.50$ \\
& ID(Harem):ID(Mare) & 0.93 & $0.09-2.14$ & $0.04-2.49$ \\
Population-level ('fixed') effects & Intercept & -14.49 & $-53.25-22.77$ & $-61.99-30.24$ \\
& Turnover_true & -1.15 & $-2.52-0.10$ & $-2.84-0.31$ \\
& log(Days) & 2.21 & $-4.09-8.74$ & $-5.40-10.18$ \\
& Age(mare) & 0.01 & $-0.00-0.03$ & $-0.01-0.04$ \\
& Season_wet & -0.72 & $-1.72-0.23$ & $-1.93-0.41$ \\
\hline
\end{tabular}

Variables are: stallion turnover (Turnover, binary: no turnover (false), turnover (true)), the log-transformed number of days between the date of dung sampling and the date of first resighting of the mare $(\log ($ Days $))$, age of the mare in months when first resighted (Age(mare)), and season (Season, dry, wet) as fixed effects; and identities of the mare (ID(Mare)) and the harem (ID(Harem)) as nested random effects. The estimates and their 90\% and $95 \%$ credible intervals (Crl) are shown. 
Table A2. Statistics of models investigating the effect of stallion turnover on the probability of observing a foal two sessions later $(\mathrm{Pr})$.

\begin{tabular}{|c|c|c|c|c|c|c|c|}
\hline Models & $\begin{array}{l}\text { Model } \\
\text { ID }\end{array}$ & pWAIC & WAIC & SE & dWAIC & dSE & W \\
\hline $\operatorname{Pr} \sim$ turnover +\# & 1 & 13.76 & 120.33 & 7.43 & 0.00 & & 0.15 \\
\hline $\operatorname{Pr} \sim A g e($ mare $)+\#$ & 2 & 13.34 & 120.98 & 6.87 & 0.64 & 4.80 & 0.11 \\
\hline $\mathrm{Pr} \sim$ turnover + Age $($ mare $)+\#$ & 3 & 15.34 & 120.99 & 7.91 & 0.66 & 2.46 & 0.11 \\
\hline $\operatorname{Pr} \sim 1+\#$ & 4 & 11.49 & 121.32 & 6.19 & 0.98 & 4.10 & 0.09 \\
\hline $\operatorname{Pr} \sim s s+\#$ & 5 & 12.75 & 121.36 & 7.12 & 1.04 & 4.62 & 0.09 \\
\hline $\operatorname{Pr} \sim$ turnover $+s s+\#$ & 6 & 15.47 & 121.48 & 8.37 & 1.14 & 2.74 & 0.08 \\
\hline $\operatorname{Pr} \sim$ Age $($ mare $)+s s+\#$ & 7 & 15.08 & 122.02 & 7.89 & 1.70 & 5.34 & 0.06 \\
\hline $\operatorname{Pr} \sim$ turnover + Age $($ mare $)+s s+\#$ & 8 & 17.03 & 122.07 & 8.93 & 1.74 & 3.84 & 0.06 \\
\hline $\operatorname{Pr} \sim$ turnover $+\log ($ Days $)+\#$ & 9 & 15.36 & 122.12 & 7.85 & 1.80 & 1.22 & 0.06 \\
\hline $\mathrm{Pr} \sim$ turnover $+\log ($ Days $)+$ Age $($ mare $)+\#$ & 10 & 17.08 & 122.90 & 8.31 & 2.58 & 2.84 & 0.04 \\
\hline $\operatorname{Pr} \sim$ turnover $+\log ($ Days $)+s s+\#$ & 11 & 17.22 & 123.46 & 8.82 & 3.12 & 3.16 & 0.03 \\
\hline $\operatorname{Pr} \sim \log ($ Days $)+\#$ & 12 & 13.05 & 123.48 & 6.60 & 3.14 & 4.32 & 0.03 \\
\hline $\operatorname{Pr} \sim \log ($ Days $)+$ Age $($ mare $)+\#$ & 13 & 15.31 & 123.63 & 7.25 & 3.30 & 4.98 & 0.03 \\
\hline $\operatorname{Pr} \sim \log ($ Days $)+s s+\#$ & 14 & 14.83 & 123.83 & 7.65 & 3.50 & 4.90 & 0.03 \\
\hline $\operatorname{Pr} \sim \log ($ Days $)+$ Age $($ mare $)+s s+\#$ & 15 & 16.84 & 123.92 & 8.30 & 3.58 & 5.58 & 0.02 \\
\hline $\operatorname{Pr} \sim$ turnover $+\log ($ Days $)+$ Age $($ mare $)+s s+\#$ & 16 & 18.98 & 124.49 & 9.53 & 4.16 & 4.40 & 0.02 \\
\hline
\end{tabular}

Models could include the effects of stallion turnover (turnover), the log-transformed number of days between the date of dung sampling and the date of first resighting of the mare $(\log (\operatorname{Days}))$, age of the mare when first resighted (Age(mare)), and season (ss) as fixed effects; and identities of the mare (ID(Mare)) and the harem $(I D($ Harem $))$ as nested random effects (identified as \# in the table). A null model with no explanatory variable was also fitted. The table reports the effective number of parameters (pWAIC), the Widely Applicable Information Criterion (WAIC), the standard error of the WAIC estimate (SE), the difference between the WAIC of each model and the WAIC of the 'top' model (i.e. the model with the lowest WAIC, in bold) (dWAIC), the 
standard error of this difference (dSE), and the Akaike weight based on WAIC (W). 
Table A3. Statistics of models investigating the effect of the number of reproductive females in harems on the probability of stallion turnover between two sessions (Pr).

\begin{tabular}{|c|c|c|c|c|c|c|c|}
\hline Models & $\begin{array}{c}\text { Model } \\
\text { ID }\end{array}$ & pWAIC & WAIC & SE & dWAIC & dSE & W \\
\hline $\operatorname{Pr} \sim N f e m+\log ($ Days $)+\#$ & 1 & 22.96 & 151.63 & 19.36 & 0.00 & & 0.97 \\
\hline $\operatorname{Pr} \sim N_{f e m}+\#$ & 2 & 20.09 & 158.65 & 19.93 & 7.02 & 5.92 & 0.03 \\
\hline $\mathrm{Pr} \sim \log ($ Days $)+\#$ & 3 & 22.89 & 167.62 & 20.01 & 15.98 & 7.96 & 0.00 \\
\hline $\operatorname{Pr} \sim 1+\#$ & 4 & 19.80 & 171.03 & 19.74 & 19.40 & 8.40 & 0.00 \\
\hline
\end{tabular}

Models could include the effects of the number of reproductive females $\left(N_{\text {fem }}\right)$ and the log-transformed number of days between the two sessions ( $\log ($ Days $))$ as fixed effects; and identities of the stallion (ID(Stallion)) and the harem $(I D($ Harem $))$ as random effects (identified as \# in the table). A null model with no explanatory variable was also fitted. The table reports the effective number of parameters (pWAIC), the Widely Applicable Information Criterion (WAIC), the standard error of the WAIC estimate (SE), the difference between the WAIC of each model and the WAIC of the 'top' model (i.e. the model with the lowest WAIC, in bold) (dWAIC), the standard error of this difference (dSE), and the Akaike weight based on WAIC (W). 
Table A4. Statistics of models investigating the effect of stallion turnover on the probability of observing a foal at the next session $(\mathrm{Pr})$.

\begin{tabular}{|c|c|c|c|c|c|c|c|}
\hline Models & $\begin{array}{l}\text { Model } \\
\text { ID }\end{array}$ & pWAIC & WAIC & SE & dWAIC & dSE & W \\
\hline $\operatorname{Pr} \sim A g e($ mare $)+s s+\#$ & 1 & 17.18 & 136.80 & 7.31 & 0.00 & & 0.20 \\
\hline $\operatorname{Pr} \sim$ Age $($ mare $)+\#$ & 2 & 15.75 & 137.13 & 6.26 & 0.34 & 3.96 & 0.17 \\
\hline $\operatorname{Pr} \sim 1+\#$ & 3 & 15.04 & 138.31 & 4.70 & 1.52 & 5.34 & 0.10 \\
\hline $\mathrm{Pr} \sim \log ($ Days $)+$ Age $($ mare $)+s s+\#$ & 4 & 18.64 & 138.39 & 7.73 & 1.58 & 2.18 & 0.09 \\
\hline $\operatorname{Pr} \sim s s+\#$ & 5 & 15.64 & 138.51 & 5.94 & 1.72 & 4.30 & 0.09 \\
\hline $\operatorname{Pr} \sim$ turnover + Age $($ mare $)+s s+\#$ & 6 & 18.61 & 139.09 & 7.74 & 2.30 & 1.24 & 0.06 \\
\hline $\operatorname{Pr} \sim$ turnover + Age $($ mare $)+\#$ & 7 & 17.57 & 139.33 & 6.70 & 2.54 & 4.04 & 0.06 \\
\hline $\operatorname{Pr} \sim \log ($ Days $)+$ Age $($ mare $)+\#$ & 8 & 17.80 & 139.67 & 6.61 & 2.88 & 4.02 & 0.05 \\
\hline $\operatorname{Pr} \sim \log ($ Days $)+s s+\#$ & 9 & 16.78 & 139.90 & 6.37 & 3.10 & 4.92 & 0.04 \\
\hline $\operatorname{Pr} \sim \log ($ Days $)+\#$ & 10 & 16.45 & 140.84 & 4.96 & 4.04 & 5.42 & 0.03 \\
\hline $\operatorname{Pr} \sim$ turnover $+s s+\#$ & 11 & 17.30 & 140.84 & 6.34 & 4.04 & 4.32 & 0.03 \\
\hline $\operatorname{Pr} \sim$ turnover $+\log ($ Days $)+$ Age $($ mare $)+s s+\#$ & 12 & 20.03 & 140.84 & 8.26 & 4.04 & 2.94 & 0.03 \\
\hline $\operatorname{Pr} \sim$ turnover $+\#$ & 13 & 16.20 & 141.01 & 5.03 & 4.22 & 5.42 & 0.03 \\
\hline $\operatorname{Pr} \sim$ turnover $+\log ($ Days $)+$ Age $($ mare $)+\#$ & 14 & 19.41 & 141.88 & 7.00 & 5.08 & 4.26 & 0.02 \\
\hline $\operatorname{Pr} \sim$ turnover $+\log ($ Days $)+\#$ & 15 & 18.04 & 143.12 & 5.38 & 6.32 & 5.50 & 0.01 \\
\hline $\operatorname{Pr} \sim$ turnover $+\log ($ Days $)+s s+\#$ & 16 & 18.75 & 143.14 & 6.94 & 6.34 & 5.16 & 0.01 \\
\hline
\end{tabular}

Models could include the effects of stallion turnover (turnover), the log-transformed number of days between the date of dung sampling and the date of first resighting of the mare $(\log (\operatorname{Days}))$, age of the mare when first resighted (Age(mare)), and season (ss) as fixed effects; and identities of the mare (ID(Mare)) and the harem $(I D($ Harem $))$ as nested random effects (identified as \# in the table). A null model with no explanatory variable was also fitted. The table reports the effective number of parameters (pWAIC), the Widely Applicable Information Criterion (WAIC), the standard error of the WAIC estimate (SE), the difference between the WAIC of each model and the WAIC of the 'top' model (i.e. the model with the lowest WAIC, in bold) (dWAIC), the 
standard error of this difference (dSE), and the Akaike weight based on WAIC (W). 
Figure 1. The probability of a stallion turnover between two consecutive sessions as a function of the number of reproductive females in the harems at the first session. The black dots show the predictions from the model, for all observations of the dataset, with the mean \pm SE of these values shown in red. For each category of the number of reproductive females, we also report the number of turnover (1) or no turnover (0) situations, also expressed as the percentage of observations within each category.

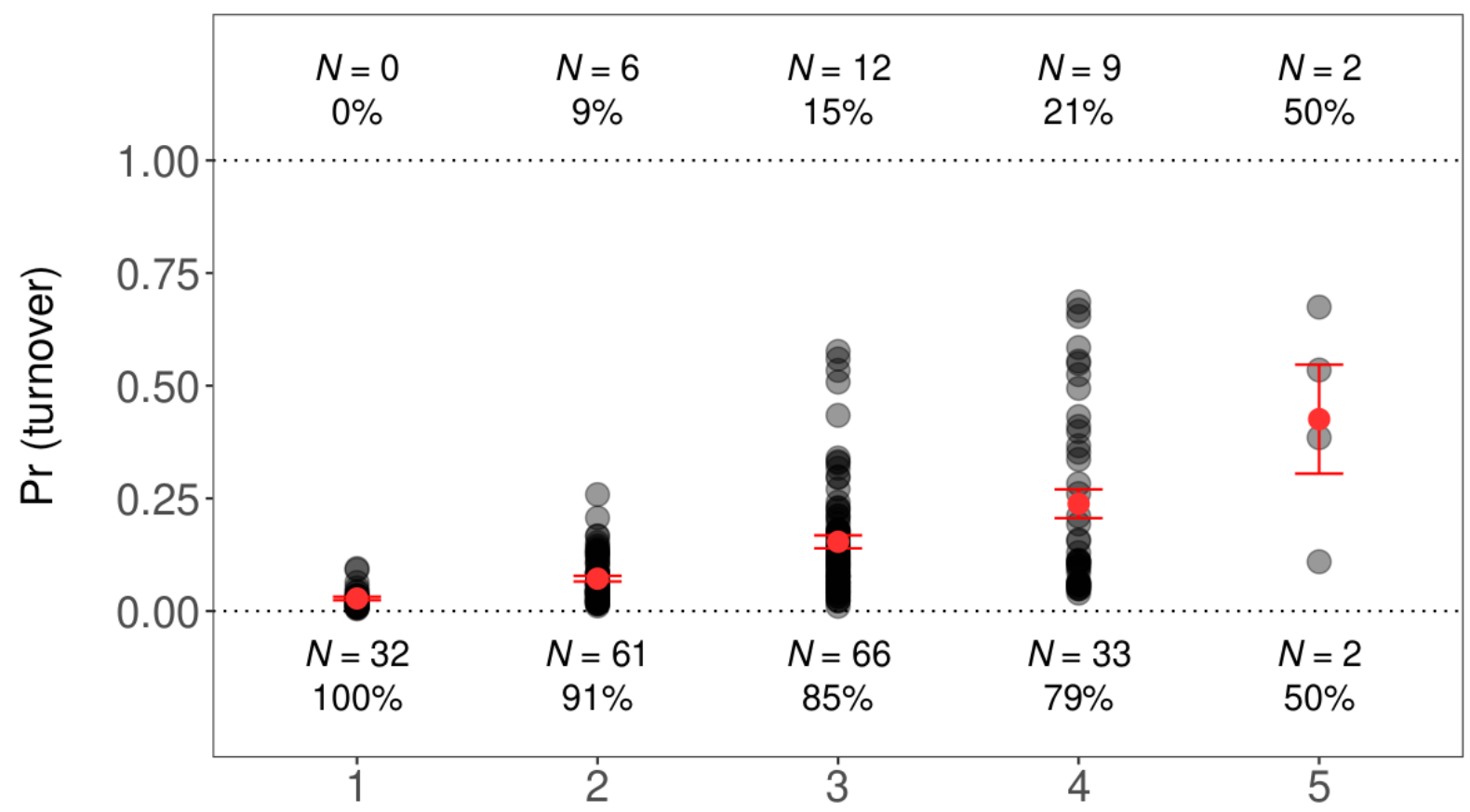

Number of reproductive females in harems 
Figure 2. The probability of observing a foal at the next session, for females that were determined pregnant in one session based on hormone analysis, in relation to whether or not the stallion was replaced in the meantime. The black dots show the predictions from the model, for all observations of the dataset, with the mean \pm SE of these values shown in red. For each category of stallion turnover, we report the number of foals observed (1) or not observed (0) at the next session, also expressed as the percentage of observations within each category.

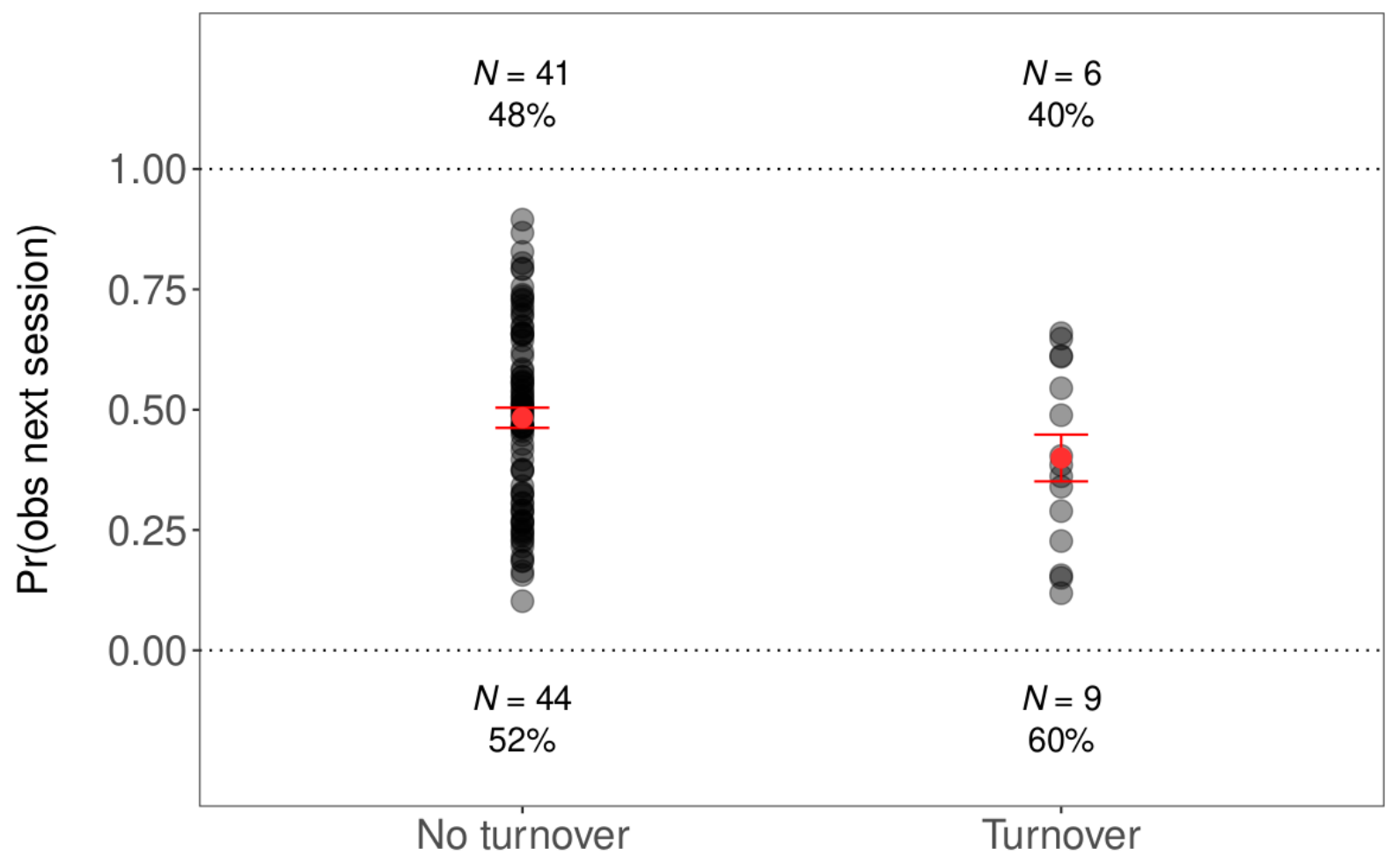


Figure A1. The probability of observing a foal two sessions later, for females that were determined pregnant in one session based on hormone analysis, in relation to whether or not the stallion was replaced in the meantime. The black dots show the predictions from the model, for all observations of the dataset, with the mean \pm SE of these values shown in red. For each category of stallion turnover, we report the number of foals observed (1) or not observed (0) two sessions later, also expressed as the percentage of observations within each category.

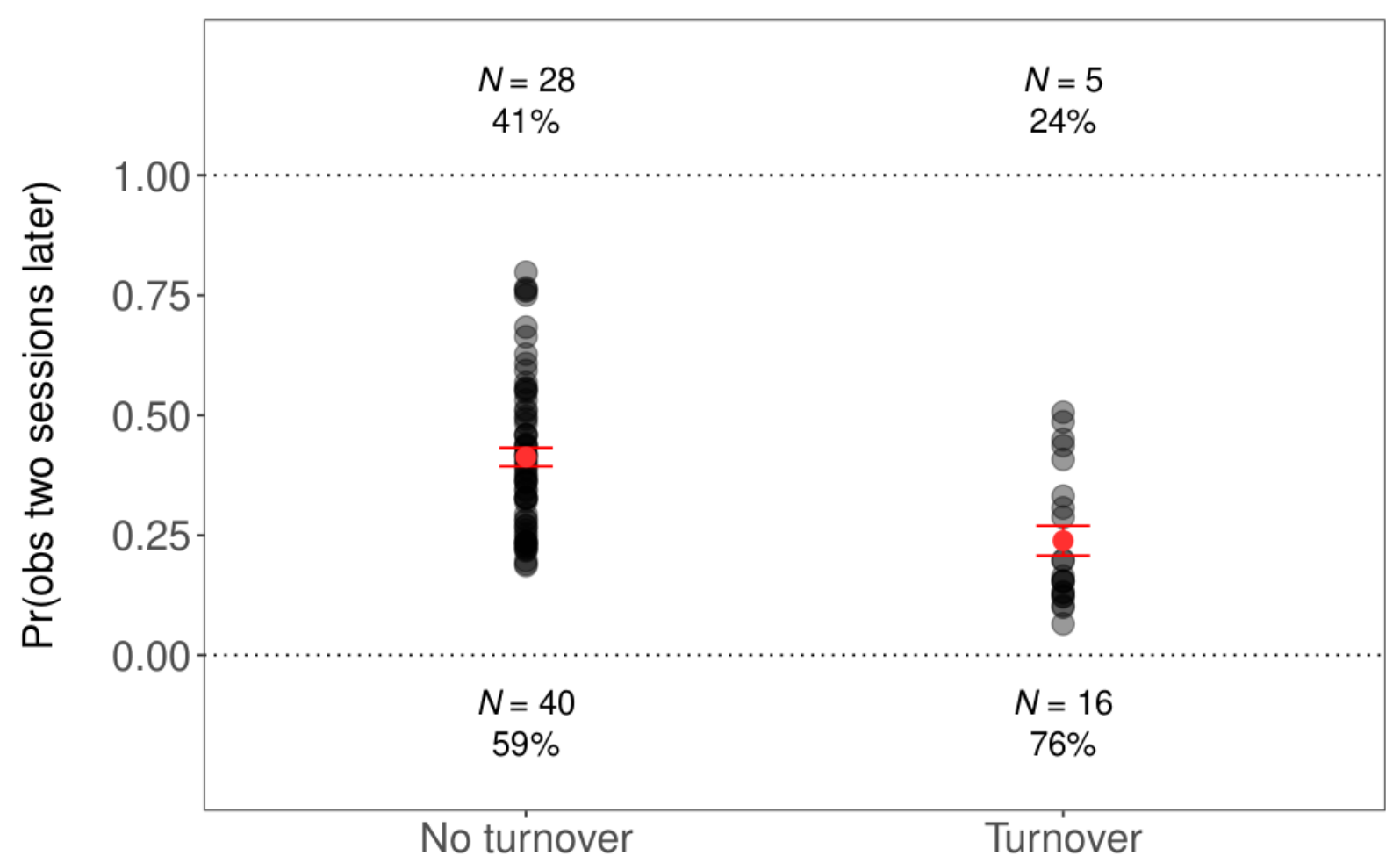




\section{APPENDIX}

Focusing on females detected in mid-pregnancy $(N=89)$, we investigated the effect of stallion turnovers on the probability of re-observing these mares with a foal two sessions later (rather than at the next session) when the stallion was replaced between the date of dung sampling and the date of the first resighting of the mare two sessions later, and when a stallion turnover had not occurred. Based on the model parameters, the probability of observing a foal two sessions later did not differ between situations when a stallion turnover occurred and those when it did not (Table A1, Fig. A1). We do note however that the point estimate for the turnover variable is more negative than in the analysis presented in the main text, and that the credible intervals are quite asymmetric around 0 . Also, the turnover variable was included in the 'top' model (model 1, Table A2). However, the null model (model 4), by definition a simpler model nested in model 1 , had a WAIC similar to the one of model 1 ( $d$ WAIC $=0.98 \pm 4.10 \mathrm{SE}$ ). This was reflected in the Akaike weights that were not much different (model 1: 0.15, model 4: 0.09). Also, another model that did not include the turnover variable was almost as good as model 1 in predicting the probability of observing a foal two sessions later (see Akaike weight of model 2 in Table A2). We should therefore conclude that, in the context of the dataset analyzed, none of the variables tested here, including the turnover variable, is informative to predict whether or not a foal would be observed two sessions after having detected a pregnancy. 